\title{
Thermal and Mechanical Analyses of W7-X Plasma Facing Components for Operation Phase 2
}

\author{
Zhongwei Wang ${ }^{\mathrm{a}}$, Jean Boscary ${ }^{\mathrm{a}}$, Felix Schauer ${ }^{\mathrm{a}}$, Wendelstein 7-X team ${ }^{\mathrm{b}}$ \\ ${ }^{a}$ Max-Planck-Institut fuer Plasmaphysik, Boltzmannstrasse 2, 85748 Garching, Germany \\ ${ }^{b}$ Author list: T. Klinger et al., Nuclear Fusion 59 (2019) 112004 doi: 10.1088/1741-4326/ab03a7
}

\begin{abstract}
After the successful short pulse operation phase 1 (OP1) of the stellarator Wendelstein 7-X with maximal plasma energies of $200 \mathrm{MJ}$, the upcoming long pulse OP2 aims at stepwise higher energies up to 18 GJ. With the knowledge of partly unexpected experimental heat load distributions on plasma facing components (PFC), their allowable loads were re-evaluated which consequently lead to some adaptation work.

The divertor target modules TM5h and TM6h were loaded more than expected during OP1. This triggered a detailed transient and stationary analysis which revealed a high sensitivity of the thermal response to the heating power distribution.

At the baffles, cracks were detected just before assembly for OP1 at the braze joints between $\mathrm{CuCrZr}$ heat sinks which carry the graphite tiles, and the stainless steel (SS) cooling pipes. Due to large temperature differences between parts of the pipes and support structure the braze becomes heavily stressed during the high thermal loads in OP2. Multiple optimization analyses led to the decision to release thermomechanical stresses by loosening the connections between the heat sinks and steel structures of the modules.

New stainless steel wall protection panels to be positioned behind the divertor pumping gaps for stationary OP2-loads of $100 \mathrm{~kW} / \mathrm{m}^{2}$ are being manufactured. Calculations were performed to optimize the intricate cooling channels and to lead as well as confirm the mechanical design for all working cases, the CFD calculation, static strength, ratcheting performance and fatigue assessment are performed in sequence.

The findings of these analyses lead also to adaptation of the plasma operating instructions for OP2.
\end{abstract}

\section{Keywords: Stellarator, Wendelstein 7-X, plasma facing components, thermomechanical analysis.}

\section{Introduction}

First plasma operation of the stellarator Wendelstein 7-X (W7-X) started at the end of 2015. During the twoyear-long operation phase 1 (OP1), short pulses were carried out with an energy limit of 200 MJ. In the upcoming OP2, the pulse length shall reach $30 \mathrm{~min}$ and the total energy of 18 GJ. The passively cooled plasma facing components (PFC) will be replaced by actively cooled ones [1]. With the current knowledge of partly unexpected OP1 experimental heat load distributions on the PFCs like the divertor target modules, baffles, and wall protection panels (Fig. 1), their allowable loads were re-evaluated. In this paper, some thermal and mechanical analysis efforts performed with ANSYS are introduced.

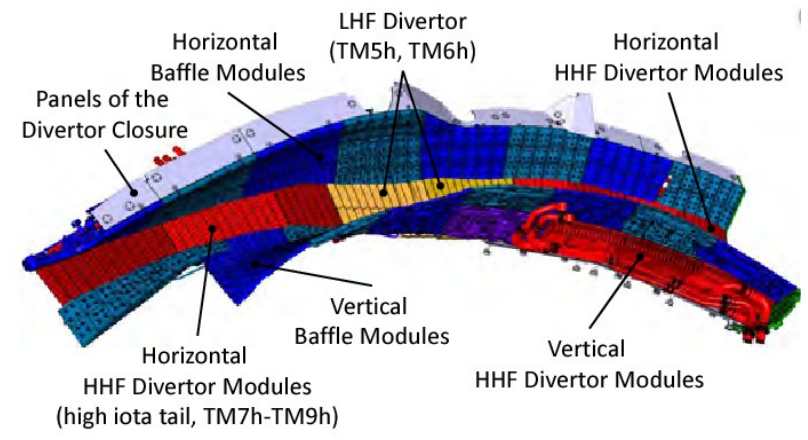

Fig. 1. Divertor unit, baffle and panels (abbreviations s. below)

\section{Divertor target modules}

The W7-X divertor consists of ten equal units, one situated above and one below the helical axis in each of the five symmetric field periods. A single unit is divided into 10 high heat flux (HHF) modules and two low heat flux (LHF) modules (see Fig. 1). The target modules (TM) $5 \mathrm{~h}$ and $6 \mathrm{~h}$ are categorized as LHF type.

The HHF modules are designed for a heat flux as high as $10 \mathrm{MW} / \mathrm{m}^{2}$, while the LHF ones' original requirement is $500 \mathrm{~kW} / \mathrm{m}^{2}$. Therefore, different materials and manufacturing techniques are employed. The HHF modules have CFC tiles on the plasma facing surface, and a copper-based interlayer connects the tiles to the $\mathrm{CuCrZr}$ heat sinks [2]. In the LHF modules, graphite tiles are bolted onto the $\mathrm{CuCrZr}$ heat sink, with a thin graphite layer "Sigraflex" located in between to compensate for surface warpings in order to achieve minimal heat resistance (Fig. 2) [3, 4]. According to the improved knowledge, the heat load on these LHF modules might be higher than expected up to $1 \mathrm{MW} / \mathrm{m}^{2}$ and locally to $6 \mathrm{MW} / \mathrm{m}^{2}$. A shifted heating position in poloidal direction makes the situation more complicated due to reduced cooling pipe contacts at some target element edges. As a result, the static temperature distribution and the transient response changes at different surface positions, and corresponding thermal analysis was performed. 


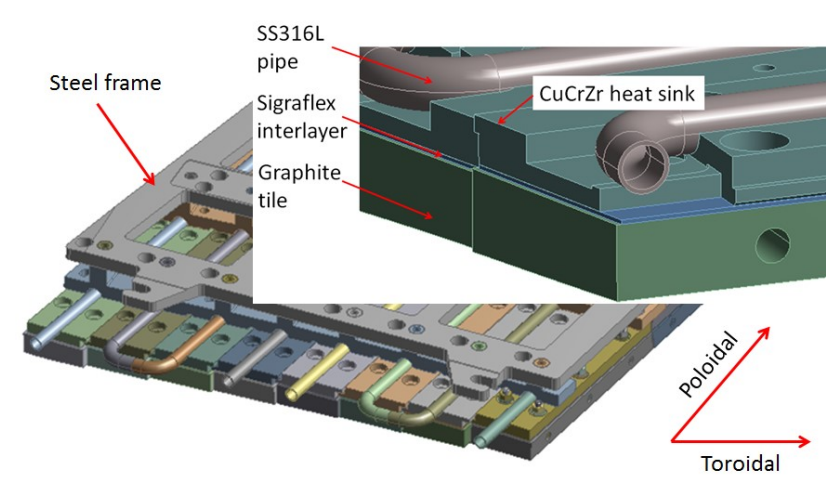

Fig. 2. TM5h/6h structure

In toroidal direction, the heat load and the target element configuration is uniform, so a representative model is built from TM5h which includes three target elements; the material distribution is also shown in Fig.2.

Both static and transient thermal analyses are performed with a finite element model of 1.2 million nodes. In the static scenario, $1 \mathrm{MW} / \mathrm{m}^{2}$ is applied over a $100 \mathrm{~mm}$ long surface in poloidal direction, and in the transient case, $6 \mathrm{MW} / \mathrm{m}^{2}$ are applied for $10 \mathrm{~s}$ at the same position with a time step of $0.1 \mathrm{~s}$. The cooling water runs at $50{ }^{\circ} \mathrm{C}$ and $2.8 \mathrm{MPa}$, and empirical temperaturedependent forced convection heat transfer coefficients are applied on the cooling pipe inner surface. Besides the designed heating position in the middle of the module, according to the experience of OP1, with some margins, the case of a heat load shift by $100 \mathrm{~mm}$ is also considered (Fig. 3). Since the heat transfer area between the pipes and the graphite surface is reduced because of the brazing requirements and the presence of the bolt connections (Fig. 4), the cooling system performance with the shifted heat load is different.

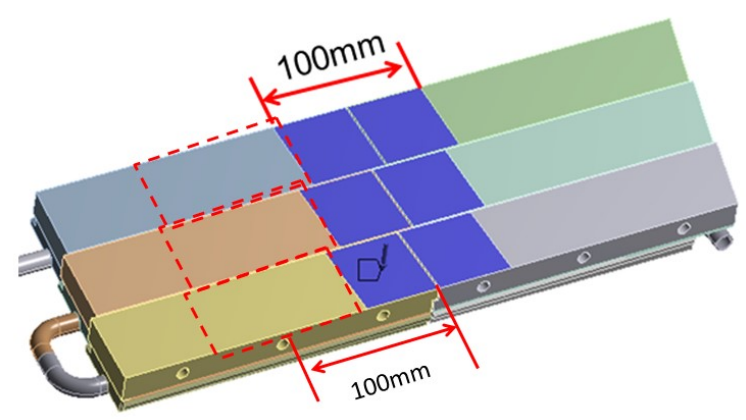

Fig. 3. Central (blue part) and shifted (dashed line) heating area on three target elements

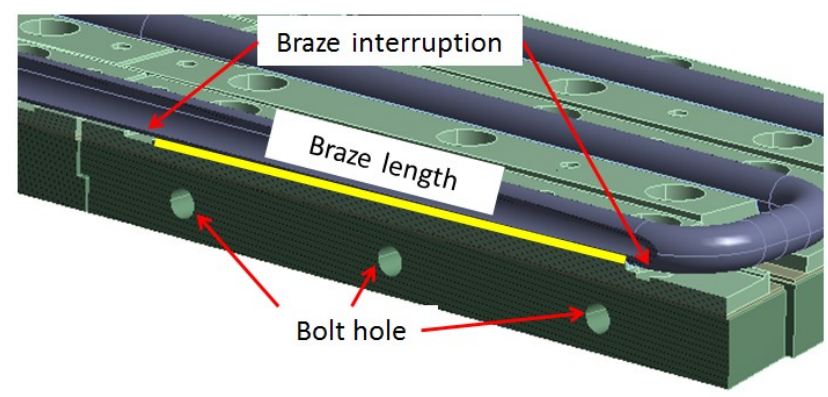

Fig. 4. Discontinuous conduction path from the graphite surface to the cooling pipe
In the static analysis, peak temperature of $1617{ }^{\circ} \mathrm{C}$ appears at the edge of the graphite tile, where it is furthest to the water cooling (Fig. 5). The maximal temperature of the $\mathrm{CuCrZr}$ heat sink reaches $678{ }^{\circ} \mathrm{C}$ which is above the allowed $\sim 450{ }^{\circ} \mathrm{C}$.

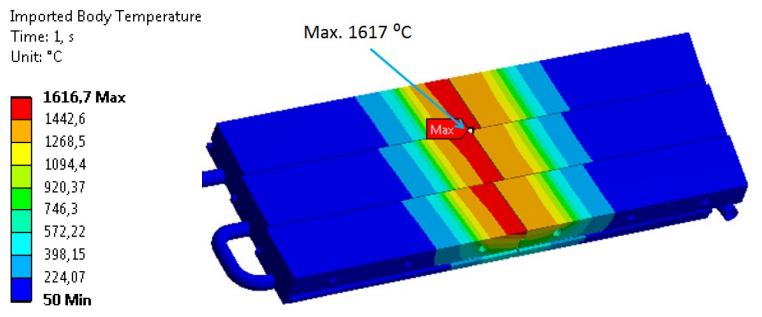

Fig. 5. Steady state temperature distribution $\left(1 \mathrm{MW} / \mathrm{m}^{2}\right.$ on the central heating area)

In the transient case, the peak temperature also appears at the edge of the graphite tile, but due to the higher heat flux $\left(6 \mathrm{MW} / \mathrm{m}^{2}\right)$, the temperature rises to $2861{ }^{\circ} \mathrm{C}$ in $10 \mathrm{~s}$. Thereafter, the temperature drops until the next pulse due to thermal diffusion (Fig. 6). This high temperature is not acceptable; in order to keep the graphite surface temperature below $2000{ }^{\circ} \mathrm{C}$, the heating time should not be longer than $5.8 \mathrm{~s}$.

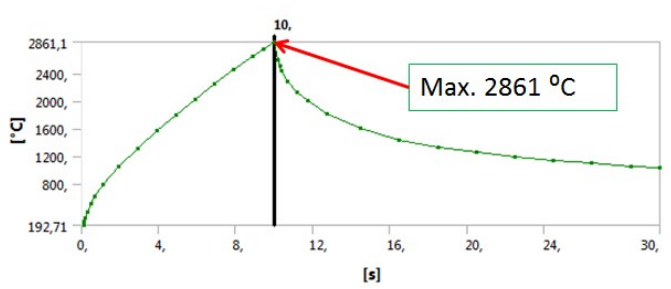

Fig. 6. Temperature history ( $6 \mathrm{MW} / \mathrm{m}^{2}$ for $10 \mathrm{~s}$, then unloaded)

The peak temperature is quite sensitive to the heating area position. In the middle of the module the cooling pipe is, due to manufacturing reasons, not bonded completely until the ends of the target element (Fig. 4). If the load is shifted to a fully cooled position (dashed in Fig. 3), the peak temperature of the graphite in the static case is reduced to $1242{ }^{\circ} \mathrm{C}$, and the $\mathrm{CuCrZr}$ heat sink temperature is also reduced to $371{ }^{\circ} \mathrm{C}$, both are within the limiting values. However, without the bolt hole through the width of the tile (Fig. 4), the peak graphite surface temperature would be $1097^{\circ} \mathrm{C}$ only.

As a result of this analysis, a static load of $1 \mathrm{MW} / \mathrm{m}^{2}$ is allowed if it is applied to a continuously cooled target element, i.e. not in the middle of a module. A transient load is allowed for $5.8 \mathrm{~s}$ in the middle of the module and for $5.3 \mathrm{~s}$ in a shifted scenario.

\section{Baffles}

The baffles are designed to protect the areas near the target modules. In addition, they are part of the divertor volume enclosure which increases the pumping efficiency (Fig. 7). There are totally 17 types of baffle modules, depending on the geometry requirements. 


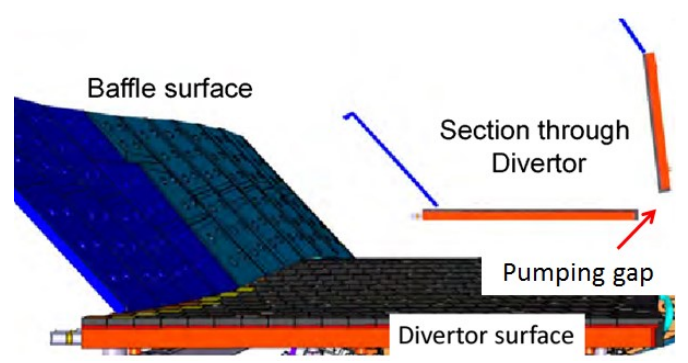

Fig. 7. Baffle position

The baffles have the same structure as the LHF target modules, the only difference is the tile size and the thinner baffle graphite tile which is bolted differently to the $\mathrm{CuCrZr}$ heat sink. During baffle manufacturing, the stainless steel cooling pipes were brazed to straight heat sink rows (cf. Fig. 8). Then a process called "3D shaping" was performed, to bend the pipes into the right geometry and weld the rows together to modules [5]. Just before installation in the plasma vessel, hot and bending cracks within the braze were discovered. These weak spots, but also the sound brazes in highly loaded areas are endangered concerning fatigue due to the cyclic thermomechanical loads. According to previous experimental and numerical analysis efforts, the lifetime of the cracked braze is quite low [6]. In order to prevent possible crack initiation and propagation through the pipe wall causing water leakage, the mechanical load on the braze must be minimized in order to achieve sufficient fatigue life.

There are large temperature gradients within a baffle module under the specified heat flux of $250 \mathrm{~kW} / \mathrm{m}^{2}$ with water cooling $\left(50{ }^{\circ} \mathrm{C}, 2.5 \mathrm{MPa}, 6 \mathrm{~m} / \mathrm{s}\right)$, see Fig. 8 . The high mechanical load on the baffle braze is mainly due to two reasons: Firstly, in the original design there is a rigid connection between the $\mathrm{CuCrZr}$ heat sinks and the supporting steel frame. In many places at the module rim there is a parallel connection of the hot frame and a cold pipe section connecting two heat sink rows (Fig. 9) which loads the braze at the corresponding ends. Secondly, only one half of the pipe circumference is brazed into a corresponding groove of the heat sink which results in a large temperature gradient across the pipe section. Thus the pipe tends to bend away from the heat sink at both ends and thus stresses the braze again at both groove ends.

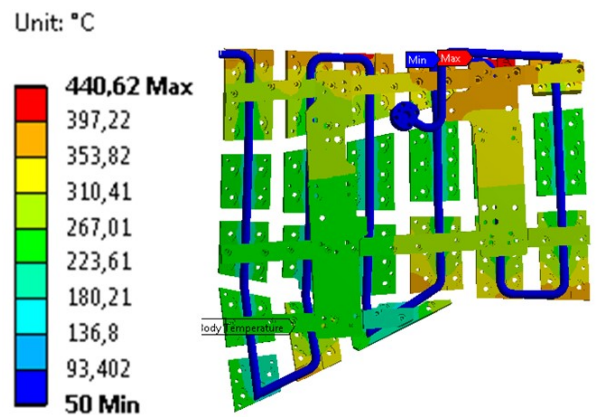

Fig. 8. Large temperature gradients in the baffle. Shown is a module from the backside without graphite tiles.

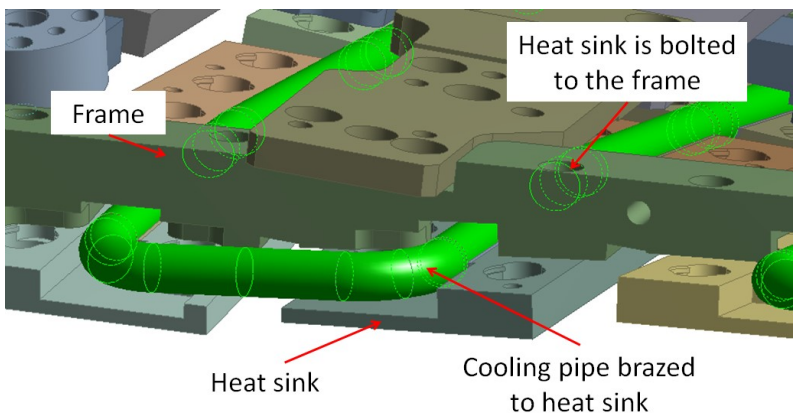

Fig. 9. Connections between cooling pipes, heat sinks and supporting frame

In order to release at least the stresses due to the parallel connections of pipes and frame, the fixed bolts between heat sinks and frame were loosened to sliding ones at the corresponding positions (Fig. 10). This way the fatigue life could be significantly increased such that it is estimated to be sufficient for the W7-X life. During operation care will be taken not to overload the critical tiles. Further experimental and theoretical investigations concerning crack propagation and maximally allowed loads are planned.

Analyses with a finite element model of 2.4 million nodes were performed to find out the optimal loosening plan, thermal loads and different flexible support plans are applied. Because the fatigue life of the braze is dominated by local plastic strain, the latter is used as optimization target (Fig. 11), elastic-perfectly-plastic stainless steel properties are used to be conservative, however, due to the complexity of the braze characteristics and the lack of experimental strain-life data, the working life can not be determined only by the analysis.

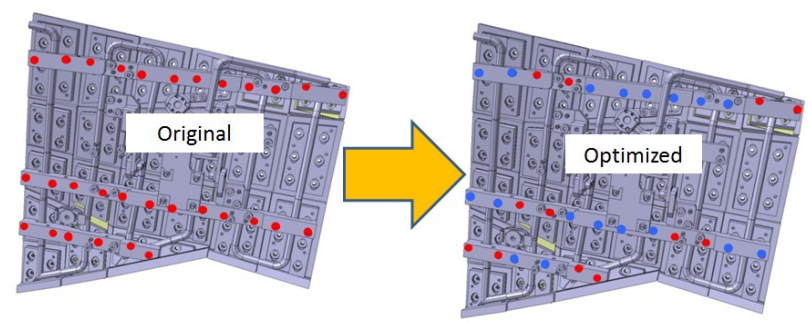

Fig. 10. Loosening plan of the BM5v baffle (red: fixed; blue: flexible) 

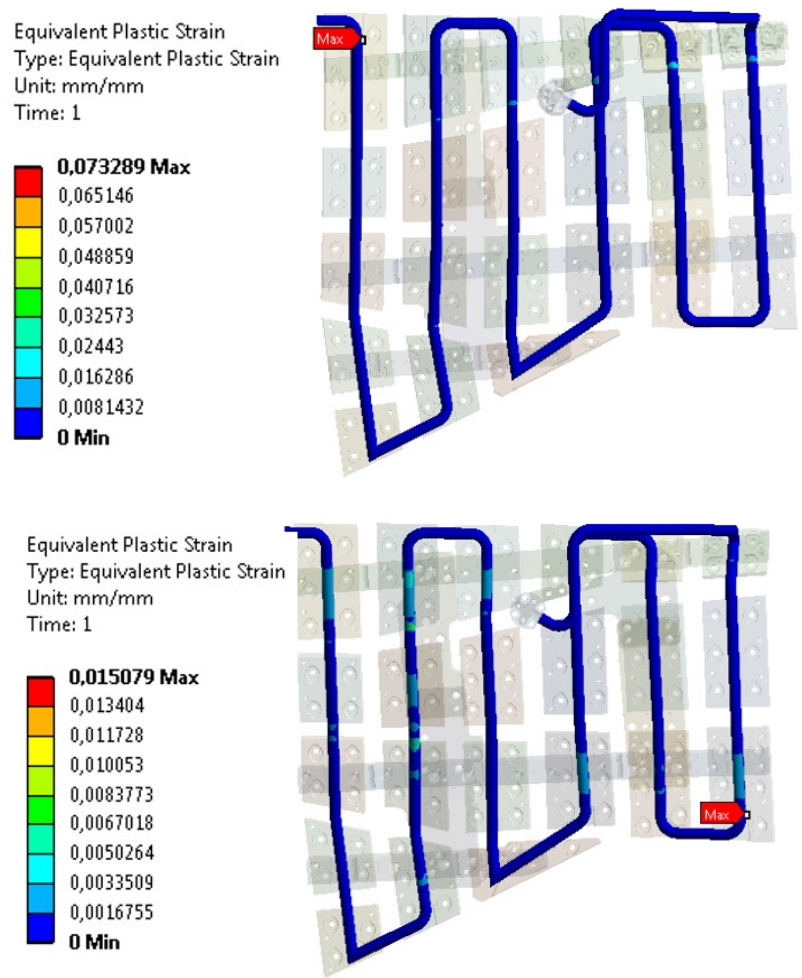

Fig. 11. Cooling pipe strain in the original (top) and optimized (bottom) designs

\section{Pumping gap panels}

The panels protect the plasma vessel wall against plasma radiation coming from the pumping gap between the horizontal and vertical divertor modules (Fig. 7). There are six different types of panels per divertor unit, series connected to one water cooling loop. They are designed for maximally $100 \mathrm{~kW} / \mathrm{m}^{2}$ heat flux; the water inlet temperature and pressure is $30{ }^{\circ} \mathrm{C}$, and $2.5 \mathrm{MPa}$, respectively.

A panel consists of a machined ground plate with channels which are covered by machined and E-beam welded sheets (Fig. 12). The design requirements include both thermal-hydraulic and mechanical issues like panel temperature, water pressure drop, static strength during the high pressure factory test and operation, ratcheting performance and fatigue life.

Therefore, different analyses were performed for each type of panel, at first, the temperature and water pressure distributions are calculated, then the ratcheting possibility is judged when the static strength requirement is fulfilled, in the end, the fatigue assessment is performed; in the next contents, the panel D023 is presented as an example.

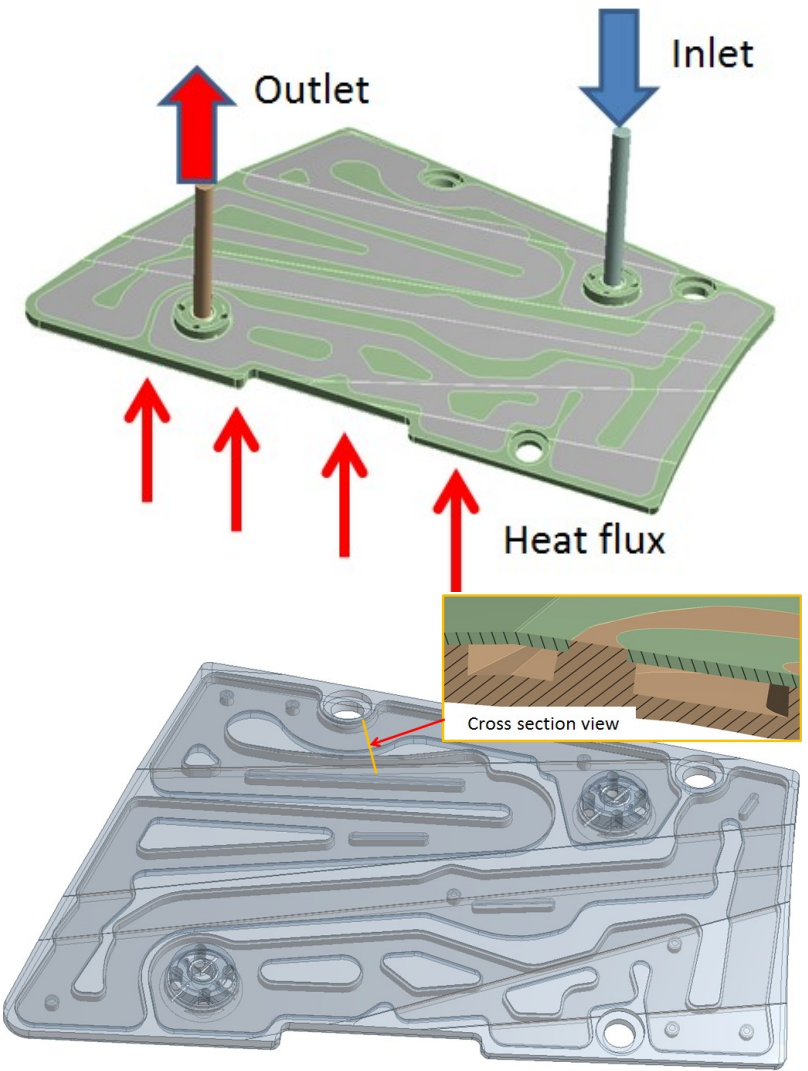

Fig. 12. Panel D023 boundary conditions (top: with channel cover; bottom: without)

A thermal-hydraulic analysis by ANSYS CFX with a finite volume model of 2.8 million elements calculates the temperature and pressure distribution as the input for the mechanical analyses.

In Fig. 13, the temperature contour of the panel and the water pressure along the channel are shown for the design flow rate of $0.27 \mathrm{~L} / \mathrm{s}$ under a heat flux of 100 $\mathrm{kW} / \mathrm{m}^{2}$ on the plasma facing surface. The whole panel is well cooled, and the pressure drop from the inlet to the outlet is $0.06 \mathrm{MPa}$ which is also acceptable.
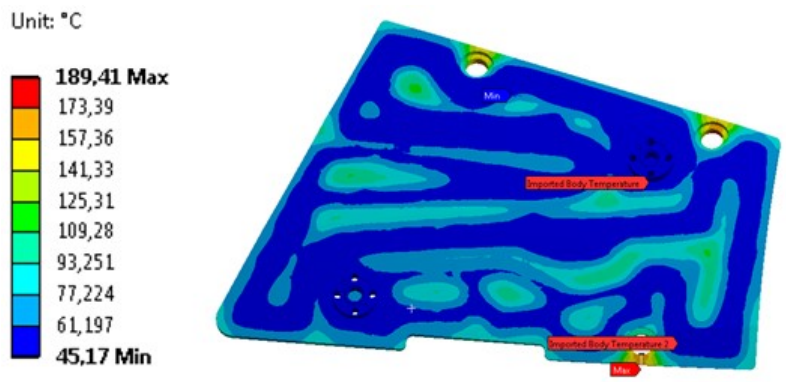

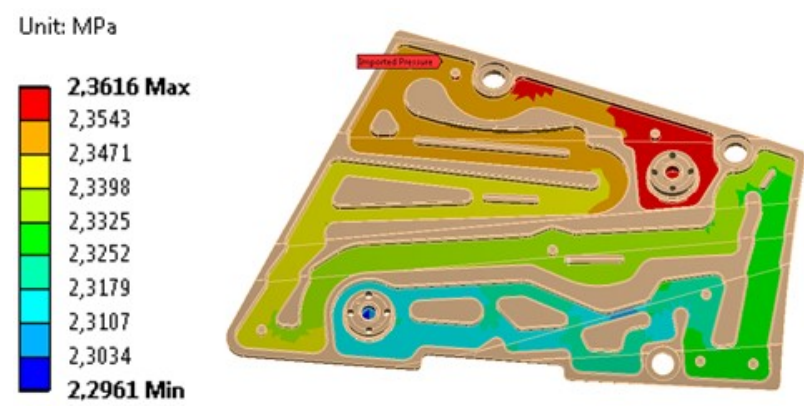

Fig. 13. Panel D023 temperature (top) and water pressure (bottom) distribution for $0.27 \mathrm{l} / \mathrm{s}$

The static strength at the $4 \mathrm{MPa}$ factory test is checked by a limit analysis with elastic-perfectly-plastic stainless steel properties, combined with the kinematic hardening model; a uniform $4 \mathrm{MPa}$ pressure is applied on the cooling channel surfaces, the fixed and flexible supports are modeled by Degrees of Freedom (DOF) constraints, which are aligned by local coordinate systems corresponding to the support orientation. the limit load is $7.5 \mathrm{MPa}$ which is much higher than the required 1.5 times of the test pressure. The ratcheting analysis simulates three operation cycles between the maximal load (imported temperature and pressure) and the standby case $\left(30^{\circ} \mathrm{C}\right.$ and $\left.1 \mathrm{MPa}\right)$, elastic-perfectlyplastic stainless steel properties are also used. During these cycles the maximum strain is steady by cycles, that means the structure is stable against ratcheting.

The fatigue assessment was performed using a local model, which is located at the maximum stress range position; in order to prevent artificial stress singularities, the effective notch stress method was employed to judge this weld. Fig. 14 shows the $0.05 \mathrm{~mm}$ radius notch model between the cover sheet and the ground plate, and elastic stainless steel properties are used. From that the fatigue life is estimated to be $550 \mathrm{k}$-cycles which is much longer than the required estimated 30 k-cycles during the operation.

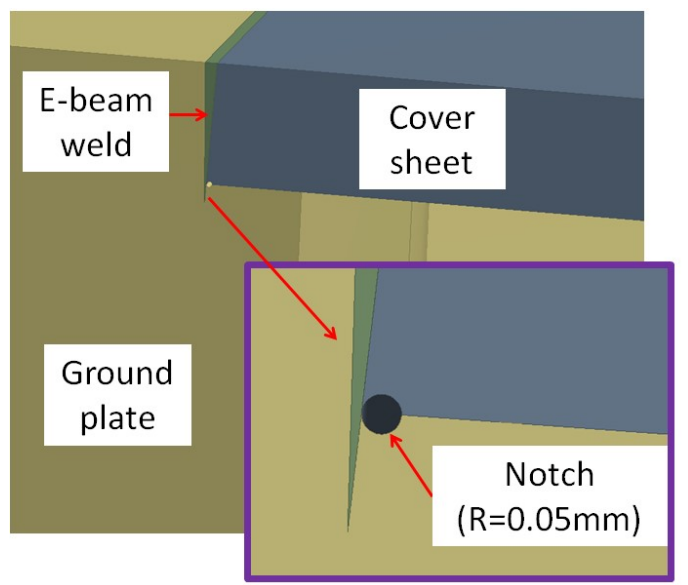

Fig. 14. Notch model in the weld fatigue calculation

\section{Conclusions}

According to the knowledge gained from OP1, some adaptation work has been carried out on the PFC to prepare for OP2. Results of the thermo mechanical analyses are:

- Sensitivity of the loading location along the LHF target element has been shown. Steady $1 \mathrm{MW} / \mathrm{m}^{2}$ heat load is only allowable with shifted heat load. Allowable heating times have been defined for the LHF TMs of $5.8 \mathrm{~s}$ (central heating) and $5.3 \mathrm{~s}$ (shifted heating) at $6 \mathrm{MW} / \mathrm{m}^{2}$.

- Reduction of the thermo-mechanical stresses of the baffles by loosening the connection to the support structure.

- The design of the cooling channel and the mechanical design of the new pumping gap panels in production have been confirmed for factory tests to ratcheting and fatigue performance.

Additional results of these efforts are beneficial instructions for plasma operation in OP2.

\section{References}

[1] R. C. Wolf et al., Performance of Wendelstein 7-X stellarator plasmas during the first divertor operation phase, Phys. Plasmas 26, 082504 (2019).

[2] J. Boscary et al., Summary of the production of the divertor target elements of Wendelstein 7-X, Fusion Eng. Des. 124 (2017) 348-351.

[3] R. Stadler et al., The in-vessel components of the experiment WENDELSTEIN 7-X, Fusion Eng. Des. 84, 305-308(2009)

[4] A. Peacock et al., Status of High Heat Flux Components at W7-X, IEEE transactions on plasma science, vol. 42, no. 3 (2014).

[5] B. Mendelevitch et al., Lessons learned from the design and fabrication of the baffles and heat shields of Wendelstein 7-X, Fusion Eng. Des. 88, 1660-1663 (2013)

[6] J. Fellinger et al., Overview of fatigue life assessment of baffles in Wendelstein 7-X, Fusion Eng. Des. 136, 292 297 (2018) 